\title{
Pengukuran Kinerja Unit Pemasaran RSI Unisma Malang Menggunakan Balanced Scorecard
}

\section{Marketing Unit Performance Measurement at Unisma Islamic Hospital Malang Using Balanced Scorecard}

\author{
Fida Rahmayanti ${ }^{1}$, David ${ }^{2}$, Tri Wahyu $S^{3}$ \\ ${ }^{1}$ Program Studi Magister Manajemen Rumah Sakit Fakultas Kedokteran Universitas Brawijaya Malang \\ ${ }^{2}$ Persada Hospital Malang \\ ${ }^{3}$ Rumah Sakit Islam Unversitas Islam Malang
}

\begin{abstract}
ABSTRAK
Berdasarkan analisis akar masalah didapatkan bahwa rendahnya pilihan pasien terhadap RSI Unisma Malang salah satunya disebabkan karena kinerja unit pemasaran dinilai kurang efektif. Oleh karena itu perlu dilakukan pengukuran kinerja unit pemasaran di RSI Unisma Malang. Salah satu metode yang dapat digunakan untuk mengukur kinerja unit yaitu dengan balanced scorecard. Tujuan dari penelitian ini adalah untuk mengetahui skor atau penilaian kinerja unit pemasaran menggunakan balanced scorecard. Metode penelitian yang digunakan adalah pendekatan deskriptif. Hasil penelitian ini menunjukkan bahwa kinerja unit pemasaran RSI Unisma Malang adalah cukup. Hasil pengukuran pada perspektif keuangan mencapai skor 1 yang artinya kinerja unit pemasaran pada perspektif keuangan telah mencapai prestasi diatas standar. Standar yang dimaksudkan adalah capaian yang diharapkan pada masing-masing indikator yang ditetapkan. Pada perspektif pelanggan mendapatkan skor -1 yang artinya kinerja unit pemasaran berdasarkan perspektif pelanggan belum sesuai standar. Pada perspektif proses bisnis internal, tahap inovasi sudah memenuhi target pencapaian bahkan melebihi target sehinga mendapatkan skor 1 . Pada tahap operasi sebagian besar mendapat skor 0 , namun terdapat satu indikator yang hanya mendapat skor -1. Hal ini menunjukkan bahwa kinerja unit pemasaran pada perspektif ini sebagian belum sesuai standar. Pada perspektif pembelajaran dan pertumbuhan mendapatkan nilai puas pada indikator kepuasan karyawan sehingga mendapat skor 1, sedangkan pada retensi karyawan mendapatkan mendapat skor 0 yang berarti sesuai dengan standar, dan untuk pelatihan karyawan mendapatkan skor -1 yang berarti dibawah standar.
\end{abstract}

Kata Kunci: Balanced scorecard, pengukuran kinerja, unit pemasaran

\begin{abstract}
Based on root cause analysis, low-preferred choice of patients for Unisma Islamic Hospital Malang is because of ineffective marketing unit performance. Therefore, marketing unit performance measurement need to be done. One method which can be used to measure unit performance is by using balance scorecard. This research aims to reveal the score or the marketing unit performance using balanced scorecard. The research method used was descriptive approach. The result from this research showed that Unisma Islamic Hospital Malang marketing unit performance was good enough. The result on finance perspective achieved score 1 which meant marketing unit performance on finance perspective was above the standard. This standard means the expected target for each indicator. On consumer perspective, achieving score -1 which meant the marketing unit performance based on consumer's perspective was below the standard. On internal business process, innovation phase was already reaching the target and scored 1. Operation phase was mostly scored 0 , and only one indicator which reached score -1. It showed that marketing unit performance on this perspective was below the standard. Learning and growing performance perspective showed satisfying scores on employee indicator which was scored 1, while employee retention was scored 0 which meant equal with the standard, and for the employees training -1 was given which meant below the standard.
\end{abstract}

Keywords: Balanced scorecard, marketing unit, performance measurement 


\section{PENDAHULUAN}

Salah satu indikator yang digunakan untuk mengukur kinerja pelayanan di rumah sakit adalah Bed Occupancy Rate (BOR). Angka BOR menggambarkan tinggi rendahnya tingkat pemanfaatan tempat tidur pada instalasi rawat inap (IRNA) di rumah sakit. Berdasarkan data sekunder dari laporan rekam medik RSI Unisma Malang, BOR pada tahun 2012 sebesar 39,1\%, tahun 2013 sebesar 53,7\%, dan tahun 2014 sebesar 57,8\%. Bed Occupancy Rate (BOR) RSI Unisma Malang tiga tahun terakhir telah menunjukkan tren peningkatan, namun belum sesuai dengan standar yang diterapkan Departemen Kesehatan.

Angka BOR yang belum sesuai standar mengindikasikan bahwa pilihan pasien terhadap RSI Unisma Malang masih rendah. Hasil studi pendahuluan menunjukkan bahwa salah satu penyebab pasien tidak memilih pelayanan rawat inap di RSI Unisma Malang yaitu dikarenakan penerapan strategi pemasaran atau promosi yang dilakukan RSI Unisma Malang kurang efektif. Penerapan strategi pemasaran merupakan salah satu indikator kinerja yang diukur pada unit pemasaran RSI Unisma Malang. Penerapan strategi pemasaran yang kurang efektif menunjukkan bahwa unit pemasaran belum melaksanakan kinerja pemasaran dengan baik.

Kinerja rumah sakit menggambarkan efektifitas dan efisiensi pelayanan yang dihasilkan dalam periode tertentu dan mengacu pada standar yang ditetapkan. Pengukuran kinerja rumah sakit merupakan suatu proses penilaian mengenai pelaksanaan kemampuan kerja rumah sakit berdasarkan standar atau indikator tertentu. Pengukuran kinerja di rumah sakit mengacu pada penggunaan sumber daya manusia dalam memberikan pelayanan, kualitas layanan, kepuasan pasien, serta efisiensi dan efektifitas rumah sakit dalam mencapai tujuan (1). Pengukuran kinerja diharapkan dapat bermanfaat sebagai evaluasi kinerja pada indikator dan periode tertentu. Evaluasi pengukuran kinerja nantinya dapat dijadikan acuan dalam peningkatan kinerja unit serta menentukan strategi pemasaran di RSI Unisma Malang.

Merancang sistem pengukuran kinerja dibutuhkan metode yang mampu memotret kinerja keseluruhan dari organisasi. Terdapat berbagai macam metode pengukuran kinerja yang dapat digunakan. Tiga diantaranya adalah balanced scorecard, Integrated Performance Measurement System (IPMS), dan SMART System (Strategic Management Analysis and Reporting Technique). Sampai saat ini balanced scorecard adalah metode yang sering digunakan untuk pengukuran kinerja. Balanced scorecard terdiri dari empat perspektif dengan menggunakan titik awal strategi sebagai dasar perancangannya. Balance scorecard juga bertujuan dalam menjabarkan visi, misi, dan tujuan organisasi (2). Metode Integrated Performance Measurement System (IPMS) adalah sistem pengukuran kinerja yang dikembangkan di Center for Strategic Manufacturing dari University of Strathclyde, Glasgow. Tujuan IPMS agar sistem pengukuran kinerja lebih kuat, terintegrasi, efektif, dan efisien. Metode ini menjadikan keinginan stakeholder menjadi titik awal dalam melakukan perancangan sistem pengukuran kinerjanya. Stakeholder tidak berarti hanya pemegang saham saja, melainkan beberapa pihak yang memiliki kepentingan atau dipentingkan oleh organisasi seperti konsumen, karyawan, dan lain sebagainya (3). SMART System merupakan metode yang dicetuskan oleh
Wang Laboratory dengan menggunakan strategi objektif sebagai titik awal perancangannya. Perspektif berdasarkan strategi obyektifnya diyakini mampu menunjang operasional perusahaan. Strategi obyektif disusun sesuai tingkatan dalam manajemen perusahaan sehingga tersusun seperti piramida. Metode ini banyak digunakan oleh perusahaan kecil dan menengah yang tidak memiliki visi, misi, dan strategi yang jelas serta orientasi yang lebih terfokus pada kinerja operasional (4).

Berdasarkan pengertian dari tiga metode pengukuran kinerja tersebut, maka yang paling sesuai untuk diterapkan pada Unit Pemasaran RSI Unisma adalah menggunakan metode balanced scorecard karena bertitik tolak pada strategi rumah sakit dan bertujuan untuk mewujudkan misi, visi, dan tujuan rumah sakit. Metode balanced scorecard bermanfaat sebagai evaluasi kinerja unit pada indikator dan periode tertentu serta nantinya dapat dijadikan acuan dalam peningkatan kinerja unit serta mengembangkan strategi pemasaran di RSI Unisma Malang.

Balanced scorecard diartikan sebagai kartu skor yang digunakan untuk mengukur kinerja dengan menyeimbangkan aspek keuangan dan non keuangan, antara jangka pendek maupun panjang, serta melibatkan faktor internal dan eksternal untuk merumuskan strategi. Balanced scorecard semakin populer karena dapat diintegrasikan dengan metode strategi bisnis yang terbukti dapat meningkatkan kinerja rumah sakit secara signifikan (5). Kinerja suatu perusahaan atau organisasi dapat dilihat dari berbagai perspektif tergantung dari karakteristik masing-masing organisasi (6). Pengukuran balanced scorecard dilakukan secara komprehensif mencakup empat perspektif yaitu keuangan, pelanggan, proses bisnis internal, serta pembelajaran dan pertumbuhan (7). Pada umumnya perusahan-perusaan ataupun organisasi hanya melakukan pengukuran berdasarkan salah satu perspektif saja, sehingga pengukuran kinerja tidak memberikan hasil yang maksimal (8). Kinerja suatu perusahaan sering diukur dengan menggunakan pengukuran kinerja tradisional yang hanya menitikberatkan pada sektor keuangan semata karena ukuran keuangan mudah dilakukan pengukurannya. Penerapan pengukuran kinerja yang seperti itu, menyebabkan perusahaan hanya berorientasi pada keuntungan jangka pendek dan cenderung mengabaikan kelangsungan hidup perusahaan dalam jangka panjang (9). Masing-masing perspektif mempunyai indikator dan sasaran strategis yang bermacam-macam. Sasaran strategis merupakan penjabaran tujuan rumah sakit atau perusahaan. Sasaran strategis pada keempat perspektif tersebut memiliki hubungan yang saling terkait $(2,5)$. Sebelum melakukan pengukuran kinerja harus menetapkan indikator yang sesuai pada setiap tujuan strategis. Agar dapat menghasilkan pengukuran kinerja yang bermanfaat maka rumah sakit harus dapat mengidentifikasi hasil yang diinginkan dan proses yang dilakukan untuk mencapai outcome tersebut (2). Rumah sakit dapat menerapkan metode balanced scorecard sebagai salah satu alat ukur penilaian kinerja untuk mencapai keberhasilan rumah sakit. Mengukur kinerja berarti memantau dan mengukur kemajuan yang sudah dicapai atas tujuan-tujuan strategis yang telah diciptakan (10). Kajian ini dilakukan untuk mengevaluasi kinerja unit pemasaran secara komprehensif dengan menggunakan model BSC, sebagai dasar dalam mengembangkan stratei pemasaran yang tepat. 


\section{METODE}

Penelitian dilaksanakan pada unit pemasaran RSI Unisma Malang pada bulan Oktober 2015. Penelitian ini menggunakan metode deskriptif yaitu mendeskripsikan indikator-indikator kinerja yang ditentukan pada unit pemasaran RSI Unisma. Indikator kinerja ditentukan melalui focus group discussion (FGD) yang dihadiri direktur rumah sakit, manajer, kepala unit pemasaran, dan staf unit pemasaran. Penentuan indikator ditentukan dengan mengacu pada teori tentang pengukuran balanced scorecard dan disesuaikan dengan kondisi RSI Unisma.

Data diperoleh melalui focus group discussion (FGD) yang bertujuan untuk menentukan indikator kinerja yang akan digunakan. Melalui FGD juga diperoleh data tentang strategi pemasaran yang telah dirancang dan pelaksanaanya. Data primer juga diperoleh dari hasil kuesioner tentang kepuasan karyawan unit pemasaran. Kuesioner dibagikan kepada empat karyawan unit pemasaran. Data sekunder didapatkan melalui laporan tahunan, laporan rekam medik, program kerja unit pemasaran, serta dokumen pelaksanaan program kerja yaitu hasil capaian kinerja unit pemasaran tahun 2014.

Berdasarkan hasil FGD, pada unit pemasaran RSI Unisma ditetapkan indikator kinerja yang meliputi empat perspektif dalam balanced scorecard yaitu perspektif keuangan, pelanggan, proses bisnis internal, serta pembelajaran dan pertumbuhan. Pengukuran dalam perspektif keuangan menggambarkan konsekuensi dari segala tindakan ekonomis yang sudah diambil. Indikator dalam perspektif keuangan unit pemasaran RSI Unisma yang ditetapkan adalah rasio ekonomi (11). Prespektif pelanggan menjelaskan cara-cara dimana nilai akan diciptakan untuk pelanggan (12). Pengukuran kinerja berdasarkan perspektif pelanggan dapat menggunakan indikator akuisisi pelanggan dan retensi pelanggan (13). Perspektif proses bisnis internal merupakan kemampuan rumah sakit untuk meningkatkan layanan melalui kegiatan-kegiatan atau proses pelayanan. Pengukuran kinerja unit pemasaran berdasarkan perspektif proses bisnis internal menggunakan dua indikator pada dua tahap yaitu tahap inovasi dan tahap operasi (14). Pada perspektif pembelajaran dan pertumbuhan, indikator kinerja yang digunakan pada unit pemasaran yaitu retensi karyawan, pelatihan karyawan, dan kepuasan karyawan. Kepuasan karyawan diukur dengan menggunakan kuesioner. Kuesioner diberikan pada minggu ketiga Oktober 2014. Kuesioner dibagikan kepada empat karyawan pada unit pemasaran RSI Unisma. Kuesioner yang dibagikan meliputi dua puluh pertanyaan. Pilihan jawaban meliputi lima kategori yaitu sangat tidak setuju, tidak setuju, ragu-ragu, setuju, dan sangat tidak setuju dengan mengacu pada skor perhitungan (15). Metode perhitungan masing-masing indikator pada keempat perspektif dapat dilihat pada Tabel 1 .
Setelah menilai masing-masing indikator dalam empat perspektif, selanjutnya dilakukan penghitungan dan penetapan skor. Balanced scorecard adalah mengukur secara seimbang antara perspektif yang satu dengan perspektif yang lainnya dengan tolok ukur masing-masing perspektif. Dalam metode balanced scorecard, kinerja diukur menggunakan skoring. Skor yang diberikan berdasarkan rating scale pada Tabel 2 (16):

Tabel 2. Penentuan skor pengukuran balanced scorecard

\begin{tabular}{cll}
\hline Skor & Nilai & \multicolumn{1}{c}{ Pengertian } \\
\hline $\mathbf{- 1}$ & Kurang & Tingkat prestasi dibawah standar \\
$\mathbf{0}$ & Cukup & Tingkat prestasi sesuai standar \\
$\mathbf{1}$ & Baik & Tingkat prestasi diatas standar \\
\hline
\end{tabular}

Sumber: Mulyadi, 2001

Penentuan skor ditentukan berdasarkan standar. Penentuan standar diperoleh dengan mempertimbangkan kesesuaian antara indikator yang ditentukan dengan target pencapaian. Penentuan skor dilakukan berdasarkan musyawarah dengan seluruh staf di unit pemasaran. Dikatakan dibawah standar apabila pencapaian dibawah target, dikatakan sesuai standar apabila hasil capaian sesuai dengan target, dan dikatakan diatas standar apabila pencapaian diatas target pencapaian.

Sebelum melakukan penilaian, perlu disusun tabel kriteria keseimbangan terhadap masing-masing perspektif dalam balanced scorecard (16). Pada tabel kriteria keseimbangan ditampilkan indikator kinerja berdasarkan empat perspektif dan dituliskan skor sesuai standar yang diinginkan yaitu skor 1 . Kriteria keseimbangan digunakan untuk mengukur keseimbangan sasaran strategik yang dicapai pada semua perspektif. Setelah memberikan skor pada masing-masing perspektif, kemudian skor dijumlahkan sebagai total skor kriteria keseimbangan. Seluruh indikator yang ditetapkan berjumlah 14 indikator, sehingga apabila masing-masing indikator diberi angka 1 maka total skor kriteria keseimbangan adalah 14.

Setelah menyusun tabel keseimbangan, selanjutnya membuat tabel pengukuran kinerja berdasarkan empat perspektif dalam balanced scorecard. Pada tabel ini harus dituliskan indikator kinerja yang akan diukur beserta target yang harus dicapai dan nilai yang telah dicapai (16). Diberi nilai 1 apabila hasil perhitungan tiap indikator melebihi dari target capaian yang ditetapkan oleh unit pemasaran RSI Unisma, nilai 0 apabila hasil sesuai dengan target, dan nilai -1 apabila hasil kurang atau belum memenuhi target.

Setelah menuliskan indikator, target, dan hasil capaian, tahap selanjutnya adalah menentukan skor. Kemudian skor seluruh indikator dijumlahkan sebagai nilai total skor kinerja. Langkah selanjutnya yaitu menghitung total skor

Tabel 1. Metode perhitungan pada masing-masing indikator

\begin{tabular}{|c|c|c|c|c|c|c|}
\hline Perspektif & Indikator & $\begin{array}{l}\text { Tujuan } \\
\end{array}$ & \multicolumn{3}{|c|}{ Metode Perhitungan } & Keterangan \\
\hline \multirow[t]{3}{*}{ Keuangan } & \multirow{3}{*}{$\begin{array}{l}\text { Rasio } \\
\text { Ekonomi }\end{array}$} & \multirow{3}{*}{$\begin{array}{l}\text { Menggambarkan kemampuan } \\
\text { menggunakan anggaran yang mencakup } \\
\text { pengelolaan keuangan, hati-hati, } \\
\text { hemat, atau boros (11) }\end{array}$} & Pengeluaran & \multirow{3}{*}{$x$} & \multirow{3}{*}{$100 \%$} & \multirow{3}{*}{$\begin{array}{l}\text { Ekonomis } \\
\text { apabila } \\
\text { nilai }<100 \%\end{array}$} \\
\hline & & & 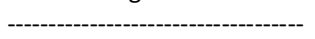 & & & \\
\hline & & & Anggaran yang ditetapkan & & & \\
\hline \multirow[t]{2}{*}{ Pelanggan } & \multirow{2}{*}{$\begin{array}{l}\text { Akuisisi } \\
\text { Pelanggan }\end{array}$} & \multirow{2}{*}{$\begin{array}{l}\text { Menunjukkan tingkat kemampuan } \\
\text { rumah sakit meraih pelanggan baru (1) }\end{array}$} & Jumlah pelanggan baru & \multirow[b]{2}{*}{$x$} & \multirow[b]{2}{*}{$100 \%$} & \multirow{2}{*}{$\begin{array}{l}\text { Target RSI } \\
\text { Unisma } \\
70 \%\end{array}$} \\
\hline & & & Jumlah total pelanggan & & & \\
\hline
\end{tabular}


Tabel 1. Metode perhitungan pada masing-masing indikator

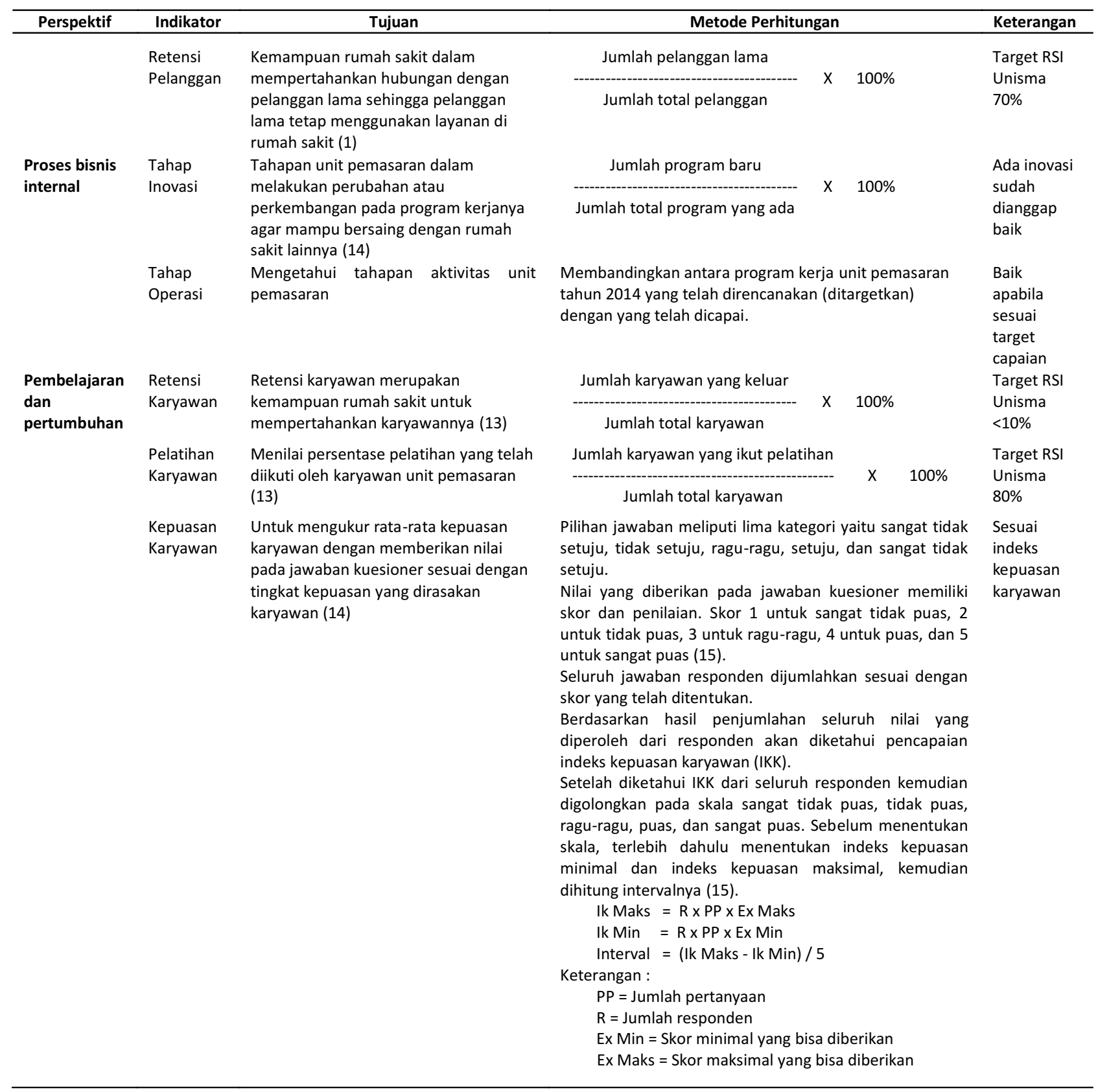

akhir. Total skor akhir dihitung berdasarkan rata-rata antara total skor kriteria keseimbangan dengan total skor hasil kinerja (15). Hasil skor akhir kemudian dicocokkan dengan standar penentuan skor yang mengacu pada Mulyadi (16).

\section{HASIL}

\section{a. Perspektif Keuangan}

Perspektif keuangan memberikan petunjuk apakah perencanaan strategi, implementasi, dan pelaksanaan unit pemasaran memberikan kontibusi atau tidak kepada peningkatan keuntungan rumah sakit. Pengukuran kinerja unit pemasaran pada perspektif keuangan menggunakan indikator rasio ekonomi pada tahun anggaran 2014.

Berdasarkan rumus perhitungan rasio ekonomi, maka didapatkan persentase rasio ekonomi unit pemasaran RSI Unisma Malang yang ditunjukkan pada Tabel 4. Rasio ekonomi sebesar $57 \%$ berarti unit pemasaran RSI Unisma Malang sudah ekonomis dalam menggunakan anggaran unit pemasaran.

Tabel 3. Rasio ekonomi unit pemasaran RSI Unisma Malang tahun anggaran 2014

\begin{tabular}{lc}
\hline Pengeluaran Tahun 2014 & 121.480 .000 \\
Anggaran yang ditetapkan & 213.780 .000 \\
\hline Rasio ekonomi & $\mathbf{5 7 \%}$ \\
\hline
\end{tabular}

Sumber: Data sekunder diolah, 2015

\section{b. Perspektif Pelanggan}

Ditinjau dari perspektif pelanggan, rumah sakit harus mampu mengidentifikasi pelanggan dan segmen pasar. 
Rumah sakit juga harus mengetahui posisinya di benak pelanggan dan memiliki kemampuan dalam memberikan nilai kepada para pelanggannya. Pada perspektif ini dapat diketahui penilaian pelanggan mengenai rumah sakit kita. Hal tersebut merupakan suatu bagian dari tugas unit pemasaran. Unit pemasaran harus mampu mengupayakan strategi yang baik dalam meraih pelanggan. Apabila rumah sakit mampu meraih jumlah pasien yang tinggi maka akan meningkatkan pendapatan rumah sakit (17). Berdasarkan rumus perhitungan akuisisi pelanggan, maka didapatkan persentase akuisisi dan retensi pelanggan RSI Unisma Malang yang ditunjukkan pada Tabel 4. Tabel 4 menunjukkan bahwa kemampuan unit pemasaran dalam mendapatkan pelanggan baru berkisar antara $43 \%$ hingga $46 \%$. Kemampuan unit pemasaran dalam mempertahankan pelanggan lama sebesar 57\% pada tahun 2012 dan 2014, sedangkan pada tahun 2013 sebesar 54\%. Angka persentase tersebut masih rendah apabila dibandingkan dengan target unit pemasaran. Angka persentase retensi pelanggan yang ditargetkan adalah $70 \%$.

Tabel 4. Kinerja Perspektif Pelanggan RSI Unisma Malang

\begin{tabular}{lrrr}
\hline & $\mathbf{2 0 1 2}$ & $\mathbf{2 0 1 3}$ & $\mathbf{2 0 1 4}$ \\
\hline Akuisisi Pelanggan & & & \\
Kunjungan pasien baru & 18.773 & 24.695 & 23.851 \\
Total kunjungan pasien & 43.174 & 54.052 & 55.359 \\
Keberhasilan mengakuisisi pasien & $\mathbf{4 3 \%}$ & $\mathbf{4 6 \%}$ & $\mathbf{4 3 \%}$ \\
Retensi Pelangan & & & \\
Kunjungan pasien lama & $\mathbf{2 4 . 4 0 1}$ & 29.357 & $\mathbf{3 1 . 5 0 8}$ \\
Total kunjungan pasien & $\mathbf{4 3 . 1 7 4}$ & $\mathbf{5 4 . 0 5 2}$ & $\mathbf{5 5 . 3 5 9}$ \\
\hline
\end{tabular}

Sumber: Data sekunder diolah, 2015

\section{c. Perspektif Proses Bisnis Internal}

Pengukuran pada perspektif ini fokus pada berbagai proses internal yang memiliki dampak pada kepuasan pelanggan dan pencapaian tujuan strategis rumah sakit. Pengukuran kinerja pada perspektif proses bisnis internal dapat digunakan untuk mengetahui keunggulan yang dimiliki oleh rumah sakit. Data menunjukkan bahwa pada tahun 2014 unit pemasaran melakukan inovasi atau penambahan program kerjanya sebesar $25 \%$ yaitu sebanyak dua program kerja dari total 8 program meliputi publikasi melalui radio dan media cetak.

Pada tahap operasi kinerja unit pemasaran dapat dievaluasi berdasarkan capaian program (Tabel 7). Secara keseluruhan terdapat tujuh program (35\%) belum dilaksanakan dan dua program (20\%) yang belum sepenuhnya terlaksana dari 22 program.

Tabel 7. Pelaksanaan program kerja unit pemasaran RSI Unisma Malang tahun 2014

\begin{tabular}{|c|c|c|}
\hline Program Kegiatan & Target & Capaian \\
\hline \multicolumn{3}{|l|}{ Promosi Kesehatan } \\
\hline Dialog Interaktif Radio & $8 x$ per bulan & $8 x$ per bulan \\
\hline Kolom kesehatan media cetak & 1x per bulan & $1 \times$ per bulan \\
\hline \multicolumn{3}{|l|}{ Entertain pihak ke-3 } \\
\hline Seminar awam & $1 x$ per bulan & $1 \times$ per tahun \\
\hline Seminar medis & $3 x$ per tahun & $2 \times$ per tahun \\
\hline
\end{tabular}

Tabel 7. Pelaksanaan program kerja unit pemasaran RSI Unisma Malang tahun 2014 (Lanjutan)

\begin{tabular}{lll}
\hline Program Kegiatan & Target & Capaian \\
\hline $\begin{array}{l}\text { Corporate Social Responsibility } \\
\text { Bakti sosial }\end{array}$ & 1x per bulan & 1x per tahun \\
Bantuan kemasyarakatan & 1x per bulan & 1xper bulan
\end{tabular}

Pengadaan alat pemasaran dan

informasi RS

Baliho

Running Text Board

Neon Box

Papan nama dokter

Petunjuk arah internal RS

Petunjuk arah eksternal RS

Brosur

Kalender

Kartu nama

Website

Video profil

$\begin{array}{ll}\text { 1x pertahun } & \text { Belum dilaksanakan } \\ \text { 1x pertahun } & \text { Belum dilaksanakan } \\ \text { 1x pertahun } & \text { Belum dilaksanakan } \\ \text { 1x pertahun } & \text { 1x per tahun } \\ \text { 4x pertahun } & \text { 4x per tahun } \\ \text { 4x pertahun } & \text { 2x per tahun } \\ \text { 6x pertahun } & \text { 6x per tahun } \\ \text { 1xpertahun } & \text { 1xper tahun } \\ \text { 4x pertahun } & \text { 4x per tahun } \\ \text { 100\% } & \text { Belum dilaksanakan } \\ \text { 1x pertahun } & \text { Belum dilaksanakan }\end{array}$

Peningkatan kualitas SDM

Pelatihan

$80 \%$

$67 \%$

Jalinan kerjasama

Kerjasama pelayanan 1x perbulan 1x perbulan

kesehatan 1xperbulan Belum dilaksanakan

Kunjungan pelayanan 2xpertahun Belum dilaksanakan

kesehatan

Evaluasi kerjasama

Pengembangan Layanan

Unggulan

Promosi klinik Herbal

Sumber: Data sekunder diolah, 2015

$100 \%$

$100 \%$

\section{d. Perspektif Pembelajaran dan Pertumbuhan}

Pada perspektif pembelajaran dan pertumbuhan, indikator kinerja yang digunakan pada unit pemasaran yaitu kepuasan karyawan, retensi karyawan dan pelatihan karyawan.

Tabel 8 menunjukkan bahwa kepuasan karyawan pada skor 320 (puas), dengan angka turn over pada unit pemasaran sebesar $17 \%$. Angka turn over dikatakan baik jika berkisar antara 10-15\%. Hal ini menunjukkan kemampuan unit dalam mempertahankan karyawannya belum baik. Dari aspek pelatihan pada tahun 2014 terdapat enam karyawan unit pemasaran, namun yang sudah diikutsertakan dalam program pelatihan sebanyak empat karyawan $(66,7 \%)$

Tabel 8. Kepuasan, retensi dan pelatihan karyawan unit pemasaran RSI Unisma Malang tahun 2014

\begin{tabular}{lr}
\hline & $\mathbf{2 0 1 4}$ \\
\hline Jumlah karyawan yang keluar & 1 \\
Jumlah total karyawan & 4 \\
Retensi karyawan & $17 \%$ \\
Jumlah karyawan yang ikut pelatihan & 4 \\
Jumlah total karyawan & 6 \\
Pelatihan karyawan & $67 \%$ \\
Skor kepuasan & 320 \\
\hline
\end{tabular}

Sumber: Data sekunder diolah, 2015

Tabel 9 menggambarkan skor kinerja unit pemasaran secara komprehensif pada empat perspektif. Data 
menunjukkan total skor kinerja adalah 1 dengan skor keseimbangan 14, sehingga reratanya adalah 0,07 yang termasuk dalam kategori cukup $(0-0,5)$ dalam kurva kinerja

Tabel 9. Pengukuran kinerja unit pemasaran RSI Unisma Malang Tahun 2014

\begin{tabular}{|c|c|c|c|}
\hline Pespektif & Target & Capaian & Skor \\
\hline \multicolumn{4}{|l|}{ Keuangan } \\
\hline Rasio ekonomi & $<100 \%$ & $57 \%$ & 1 \\
\hline \multicolumn{4}{|l|}{ Pelanggan } \\
\hline Retensi pelanggan & $70 \%$ & $43 \%$ & -1 \\
\hline Akuisisi pelanggan & $70 \%$ & $57 \%$ & -1 \\
\hline \multicolumn{4}{|l|}{ Proses bisnis Internal } \\
\hline $\begin{array}{l}\text { Tahap inovasi } \\
\text { Tahap operasi }\end{array}$ & Ada inovasi & $25 \%$ & 1 \\
\hline Promosi Kesehatan & $100 \%$ & $100 \%$ & 1 \\
\hline Entertain pihak ke-3 & $80 \%$ & $38 \%$ & -1 \\
\hline $\begin{array}{l}\text { Corporate Social } \\
\text { Responsibility }\end{array}$ & $80 \%$ & $55 \%$ & 0 \\
\hline $\begin{array}{l}\text { Pengadaan alat } \\
\text { pemasaran dan } \\
\text { informasi RS }\end{array}$ & $70 \%$ & $50 \%$ & 0 \\
\hline $\begin{array}{l}\text { Peningkatan kualitas } \\
\text { SDM }\end{array}$ & $80 \%$ & $67 \%$ & 0 \\
\hline Jalinan kerjasama & $100 \%$ & $34 \%$ & 0 \\
\hline $\begin{array}{l}\text { Pengembangan } \\
\text { Layanan Unggulan }\end{array}$ & $100 \%$ & $100 \%$ & 1 \\
\hline \multicolumn{4}{|l|}{$\begin{array}{l}\text { Pembelajaran } \\
\text { dan Pertumbuhan }\end{array}$} \\
\hline Kepuasan karyawan & Puas & Puas & 1 \\
\hline Retensi karyawan & $<10 \%$ & $17 \%$ & 0 \\
\hline Pelatihan karyawan & $80 \%$ & $67 \%$ & 1 \\
\hline \multicolumn{3}{|c|}{ Total Skor Kinerja } & 1 \\
\hline
\end{tabular}

Sumber: Data sekunder diolah, 2015

\section{DISKUSI}

Hasil menunjukkan bahwa secara keseluruhan kinerja unit pemasaran RSI Unisma adalah cukup, hal ini berarti bahwa kinerja sudah sesuai dengan standar yaitu target capaian yang telah ditetapkan oleh RSI Unisma meskipun pada beberapa dimensi belum semua memenuhi standar.Hasil pengukuran kinerja menggunakan balanced scorecard dapat digunakan untuk menentukan pencapaian visi, misi, serta tujuan RSI Unisma serta dijadikan dasar memetakan strategi RSI Unisma Malang berdasarkan empat perspektif (18). Skor yang didapatkan pada perspektif keuangan menunjukkan bahwa unit pemasaran telah mampu mengelola keuangan secara efektif dan efisien. Pada perspektif pelanggan masih menunjukkan skor dibawah standar. Hal ini berarti kinerja pemasaran belum mampu menarik jumlah pelanggan serta mempertahankan pelanggan. Hal ini akan berdampak pada keuntungan yang akan dihasilkan rumah sakit. Pada perspektif proses bisnis internal sesuai dengan standar capaian meskipun terdapat beberapa indikator yang belum berjalan baik. Pada perspektif pembelajaran dan pertumbuhan sudah sesuai standar, namun untuk pelatihan karyawan belum seluruhnya tercapai.

Setelah mengetahui kinerja unit pemasaran pada masingmasing perspektif, nantinya dapat dirumuskan perbaikan- perbaikan terhadap perspektif yang masih kurang baik dan lebih meningkatkan perspektif yang sudah optimal. Upaya yang dapat dilakukan RSI Unisma untuk peningkatan kinerja yaitu pada perspektif pelanggan dapat digali mengenai harapan pelanggan sehingga akan membawa rumah sakit lebih dekat dengan pelanggannya dan membuat seluruh orang dalam organisasi terlibat dalam upaya memberi kepuasan kepada pelanggan. Pada perspektif proses bisnis internal dapat diupayakan untuk memotivasi para pegawai untuk melakukan pelayanan sebagai bagian dari mata rantai pelanggan dan pemasok internal. Pada perspektif pembelajaran dan pertumbuhan, strategi awal yang dapat dilakukan yaitu dengan menambah sumber daya manusia yang kompeten. Apabila penambahan jumlah karyawan belum memungkinkan, dapat mengupayakan peningkatan kompetensi karyawan yang sudah ada dengan mengikutkan pelatihan khususnya terkait strategi pemasaran. Selain itu perlu ditingkatkan monitoring dan motivasi dari manajer unit pemasaran agar dengan jumlah karyawan yang minimal dapat menghasilkan kinerja yang sesuai dengan yang ditargetkan dan sesuai dengan visi, misi, dan tujuan RSI Unisma. Pada perspektif keuangan meskipun sudah melebihi target, namun tetap dipertahankan dengan mengidentifikasi berbagai pemborosan yang mungkin akan terjadi. Hal yang paling penting pada pelaksanaan upaya-upaya tersebut adalah perlunya membangun komitmen untuk melakukan suatu perubahan dengan melakukan evaluasi atas perilaku yang diharapkan tersebut. Sebaiknya dilakukan monitoring serta evaluasi dalam kurun waktu 3 bulan, 6 bulan, atau 12 bulan (19).

Peningkatan kinerja rumah sakit perlu dilakukan untuk memberikan pelayanan yang berkualitas kepada masyarakat (10). Masyarakat selalu mengharapkan dan menginginkan kualitas pelayanan yang baik dari rumah sakit, sehingga rumah sakit dituntut untuk selalu berusaha meningkatkan kinerja dan pelayanan kepada pasien (20). Metode balanced scorecard menjadi pilihan dalam mengatasi permasalahan kinerja pemasaran di RSI Unisma karena metode ini sangat efektif untuk menentukan kinerja rumah sakit secara akurat dan komperehensif (21). Konsep balanced scorecard pada dasarnya merupakan penerjemahan strategi dan tujuan yang ingin dicapai oleh suatu organisasi dalam jangka panjang, yang kemudian diukur dan dimonitor secara berkelanjutan. Penerapan balanced scorecard di RSI Unisma Malang tidak hanya merupakan alat penilaian kinerja yang bertujuan untuk peningkatan kualitas layanan di rumah sakit, namun sebagai suatu sistem manajemen strategis dalam penjabaran teknis visi dan misi RSI Unisma Malang (22).

Pengukuran kinerja yang dilakukan pada unit pemasaran RSI Unisma dilakukan pula oleh Aji Dwi Prihananto di Rumah Sakit Kristen Tayu Pati (23). Persamaan penelitian ini adalah penilaian kinerja menggunakan balanced scorecard serta objek penelitian sama-sama berbentuk rumah sakit dan diterapkan untuk menjabarkan visi, misi, serta tujuan rumah sakit. Perbedaan penelitian penelitian ini adalah penerapan balanced scorecard pada Rumah Sakit Kristen Tayu Pati hanya memfokuskan pada manajemen perusahaan. Penelitian ini menunjukkan bahwa konsep BSC dapat digunakan untuk mengukur kinerja unit pemasaran secara komprehensif dan memberikan informasi stratejik pada organisasi. Monitoring dan evaluasi kinerja perlu dilakukan secara berkelanjutan untuk menjamin pencapaian strategi organisasi. 


\section{DAFTAR PUSTAKA}

1. Lailiyah S. Pengukuran Kinerja Rumah Sakit dengan Balanced Scorecard (Studi Kasus pada Rumah Sakit Umum Daerah Ngudi Waluyo Wlingi). Jurnal IImiah Mahasiswa FEB. 2014; 2(1).

2. Kaplan RS and Norton DP. Balanced Scorecard: Menerapkan Strategi Menjadi Aksi. Jakarta: Erlangga; 1996.

3. Bititci US, Carrie AS, and Turner T. Integrated Performance Measurement Systems: A Reference Model. In: Schonsleben P and Buchel A (Eds). Organizing the Extended Enterprise. Switzerland: Springer Science; 1998.

4. Ghalayani AM and Noble JS. The changing of performance Measurement. International Journal of Operations \& Production Management. 1996; 16(8): 63-80.

5. Rangkuti F. SWOT Balanced Scorecard. Jakarta: Gramedia; 2013.

6. Susilo J. Kinerja Layanan Universitas Islam Indonesia Diukur dengan Pendekatan Balanced Scorecard. Jurnal IImu-ilmu Sosial. 2007;30(64):157-174.

7. Handayani BD. Pengukuran Kinerja Organisasi dengan Pendekatan Balanced Scorecard pada RSUD Kabupaten Kebumen. Jurnal Dinamika Manajemen. 2011; 2(1): 78-91.

8. Hermawan S. Penerapan Balanced Scorecard Sebagai Alat Implementasi Strategi Dalam Upaya Meningkatkan Kinerja Universitas Muhammadiyah Sidoarjo. Jurnal Ekonomi Bisnis dan Akuntansi. 2008; 11(2): 1-18.

9. Arimbawa IMW dan Putri IGAMAD. Analisis Penilaian Kinerja Keuangan dan Non Keuangan PT. BPR Dharmawarga Utama. Jurnal Akuntansi Universitas Udayana. 2014; 8(1): 260-73.

10. Aprilliani WA, Kartinah N, dan Hardiati RSW. Analisis Kinerja Instalasi Farmasi di BLUD Rumah Sakit Kota Banjarbaru dengan Metode Balanced Scorecard Berdasarkan Perspektif Keuangan dan Perspektif Pelayanan Periode 2012-2014. Jurnal Pharmascience. 2015; 2(2): 88-102.

11. Supriadi IBPE, Herawati NT, dan Adiputra IMP. Analisis Pengaruh Sistem Pengendalian Internal, Organizational Citizenship Behaviour dan Good Governance Terhadap Kinerja Organisasi Berdasarkan Perspektif Balanced Scorecard (Studi Kasus Pada Dinas Pendapatan Kabupaten Buleleng). Jurnal IImiah Mahasiswa Akuntansi S1. 2014; 2(1): 1-12.
12. Dhipiya FY, Tanuwijaya H, dan Sutomo E. Audit Sistem Informasi Instlasai Rawat Inap Berdasarkan Prespektif Pelanggan Balanced Scorecard Menggunakan Standar COBIT 4.1 (Studi Kasus pada Rumah Sakit Umum Haji Surabaya). Jurnal Sistem informasi dan Komputer Akuntansi. 2012; 1(1): 1-8.

13. Sipayung F. Balanced Scorecard: Pengukuran Kinerja Perusahaan dan Sistem Manajemen Strategis. Jurnal Manajemen Bisnis. 2009;2(1):7-14.

14. Utama NA, Hariadi S, dan Bambang A. Analisis Pengukuran Kinerja Rumah Sakit dengan Pendekatan Balanced Scorecard (Studi Kasus pada RSUD Prof. Dr. Soekandar Mojosari). Jurnal Ilmiah Mahasiswa FEB. 2013; 1(2): 1-26.

15. Sugiyono. Statistik untuk Penelitian. Bandung: Alfabeta; 2002.

16. Mulyadi. Balanced Scorecard: Alat Manajemen Kontemporer untuk Pelipatgandaan Kinerja Keuangan Perusahaan. Jakarta: Salemba Empat; 2001.

17. Ayu FD, Satibi, dan Fudholi A. Analisis Kinerja Instalasi Farmasi Rumah Sakit $X$ Purwokertoditinjau dari Perspektif Customer Balanced Scorecard. Jurnal IImiah Farmasi. 2015; 10(1): 28-32.

18. Norreklit H. The Balance on the Balanced Scorecard a Critical Analysis of some of its Assumptions. Journal Management accounting research. 2000; 11(1): 6588.

19. Rumintjap ML. Penerapan Balanced Scorecard sebagai Tolak Ukur Pengukuran Kinerja di RSUD Noongan. Jurnal Riset Ekonomi, Manajemen, Bisnis dan Akutansi. 2013; 1(3): 841-850.

20. Utama A. Analisis Pengaruh Persepsi Kualitas Pelayanan terhadap Kepuasan Pelanggan Rumah Sakit Umum Cakra Husada Klaten. Jurnal Optimasi Sistem Industri. 2003; 1(2): 96-110.

21. Ciptani MK. Balanced Scorecard sebagai Pengukuran Kinerja Masa Depan. Jurnal akuntansi dan Keuangan. 2004; 2(1): 21-35.

22. Fathoni dan Kesuma I. Analisis Penilaian Kinerja Rumah Sakit dengan Penerapan Balanced Scorecard (Studi Kasus Rumah "ABC"). Jurnal Sistem Informasi. 2010; 2(3): 48-57.

23. Prihananto AD. Penerapan Balanced Scorecard sebagai Tolok Ukur Penilaian Kinerja pada Badan Usaha Berbentuk Rumah Sakit (Studi Kasus pada Rumah Sakit Kristen Tayu Pati). [Skripsi]. Universitas Katolik Soegijapranata, Semarang. 2006. 